\title{
O PRINCÍPIO DA SEPARAÇÃO DE PODERES E A PONDERAÇÃO DE COMPETÊNCIAS: UMA ANÁLISE CRÍTICA A PARTIR DA DECISÃO SOBRE A FOSFOETANOLAMINA
}

\section{THE PRINCIPLE OF SEPARATION OF POWERSAND PROCEDURAL BALANCING: A CRITICAL ANALYSISOF THE PHOSPHOETHANOLAMINE DECISION}

\author{
Maria Valentina de Moraes $^{1}$ \\ Mônia Clarissa Hennig Leal ${ }^{1}$
}

Recebido em: 23/10/ 2016 Aceito em: 22/12/2016

moniah@unisc.br mariavalentina.23@hotmail.com
Resumo: A judicialização do direito à saúde é um fenômeno crescente em nosso ordenamento, o que resta demonstrado, dentre outros aspectos,com a busca do Poder Judiciário para a obtenção da chamada "pílula do câncer". Diante da ausência de regulamentação para a utilização da substância fosfoetanolamina e de registro da mesma junto à Agência Nacional de Vigilância Sanitária - Anvisa, o Supremo Tribunal Federal proferiu decisão suspendendo a eficácia de liminares que determinavam o seu fornecimento e permitiam sua utilização. O Congresso Nacional, por sua vez, editou uma lei autorizando o seu uso, a qual teve, posteriormente, sua eficácia suspensa pela mais alta Corte brasileira.Nesse cenário, busca-se estudar, frente às diferentes posições adotadas por esses dois Poderes, o papel reservado ao princípio da separação de Poderes e à discussão acerca da "última palavra" no contexto de uma democracia. Para tanto,utiliza-se o método dedutivo, sendo analisadas as decisões envolvendo a liberação da substância fosfoetanolamina sintética, bem como a lei que autorizou seu uso, a fim de perceber como se estabeleceu, no caso, a relação entre os Poderes Legislativo e Judiciário.Buscou-se, ainda, na lógica da ponderação de competências, obter elementos que permitissem compreender e questionar o atual entendimento acerca do princípio da separação de Poderes.Frente a isto, após uma breve abordagem sobre o fenômeno da judicialização e a relação entre Poderes no país, passou-se à análise das decisões envolvendo a liberação e uso da fosfoetanolamina sintética, desde a suspensão das liminares judiciais, passando pela edição da Lei n. 13.269/2016 (regulamentando sua utilização) até a declaração de inconstitucionalidade da mesma, analisando-se, então, nesse contexto, a dinâmica da separação de poderes pela lógica da ponderação. Pode-se observar, assim, que, por meio da ponderação de competências e do desenvolvimento de um diálogo institucional, decisões poderiam ser tomadas pelos Poderes Legislativo e Judiciário de forma mais harmônica, sendo possível, dessa forma, a superação de decisões judiciais, desde que estas encontrem respaldo constitucional e embasamento suficiente, diferentemente do que ocorreu no caso ora analisado.

Palavras-chave: Supremo Tribunal Federal. Congresso Nacional. Ponderação. Princípio da Separação de Poderes. Fosfoetanolamina.

\begin{abstract}
The judicialization of the right to health is a crescent phenomenon, which is also established with a pursuit for the Judicial Power in terms of access to the so called "cancer pill". Given the absence of regulation for the use of phosphoethanolamine and its registry at the National Sanitary Surveillance Agency, the Brazilian Supreme Court uttered decisions suspending the liminal that determines the supply and use of the substance. The National Congress, on the other hand, edited a law permitting the use of the "cancer pill", having, later, its effectiveness suspended by the Court. In this scenery, this work seeks to analyze the principle of separation of powers and the aspect of the "final word" in the Brazilian constitutional jurisdiction, in case of different positions adopted by the two branches. So, were analyzed the decisions involving the liberation of synthetic phosphoethanolamine and the law that permitted its use, trying to establish the relation between Legislative and Judiciary. The study also aims to analyze the procedural balancing theory, considering elements that allow questioning the principle of separations of powers as it is understood today. Therefore, after
\end{abstract}

\footnotetext{
${ }^{1}$ Universidade de Santa Cruz do Sul - UNISC - Santa Cruz do Sul - Rio Grande do Sul - Brasil
} 
an approach about the phenomenon of judicialization and the relation between branches, is made an analysis of decisions involving the release an use of phosphoethanolamine, from the suspension of judicial orders to the edition of Law 13.269/2016 and its declaration of your unconstitutionality, in terms to identify, in this context, the dynamic of separation of powers in a balancing perspective. It can be observed that, with a procedural balancing and development of an institutional dialog, Legislative and Judiciary could take harmonic decisions, being possible to overcome a judicial decision, provided that this find constitutional support and sufficient basis.

Keywords: Brazilian Supreme Court. National Congress. Balancing. Principle of Separation

of Powers. Phosphoethanolamine.

\section{INTRODUÇÃO}

Com o aumento das demandas que chegam ao Poder Judiciário buscando a efetivação do direito à saúde - principalmente através de pedidos de medicamentos - as relações que se estabelecem entre os Poderes Executivo, Legislativo e Judiciário, tornam-se, cada vez mais, alvo de debates. Discussões quanto às competências de cada Poder e as intervenções do Poder Judiciário trazem a tona importantes questionamentos, os quais refletem diretamente na promoção e proteção de direitos fundamentais sociais.

Através de uma análise das decisões envolvendo a autorização para o uso da fosfoetanolamina sintética, especialmente da Suspensão de Tutela Antecipada 828 - que suspendeu o efeito das liminares que determinavam o fornecimento da "pílula do câncer" -, e da Ação Direta de Inconstitucionalidade 5.501, que, por sua vez, declarou inconstitucional a Lei 13.269/2016, que permitia a comercialização, fornecimento e uso da fosfoetanolamina, busca-se analisar como se deram as relações entre o Poder Legislativo e Judiciário, com decisões opostas sobre o mesmo tema.

Em meio a edição da lei e suspensão de sua eficácia pelo Judiciário, em posicionamentos totalmente distintos, Legislativo e Judiciário reforçaram a inexistência de um diálogo entre os Poderes e demonstraram a falta de harmonia entre os Poderes do Estado em nosso país. Nessa linha, é necessário observar o papel destinado ao Princípio da Separação de Poderes e, também, a divisão de competências entre os Poderes.

Com a análise das decisões citadas e da Lei 13.269/2016, utilizando-se da lógica de ponderação de competências de Klatt, buscou-se entender a relação entre a última palavra da jurisdição constitucional, dada pelo Supremo Tribunal Federal, e possibilidade de superação dessa pelos demais Poderes. Assim, diante da possibilidade - afirmada pelo mais alto Tribunal brasileiro de que suas decisões sejam superadas, e analisando os fundamentos suscitados nas decisões e o embasamento da referida lei, buscou-se compreender, no caso concreto, a viabilidade de mencionada superação.

Pode se perceber que, para que haja a superação de um entendimento firmado pelo Judiciário, seria preciso que a nova interpretação possuí-se respaldo constitucional e argumentos que demonstrassem o porquê de ser a interpretação mais adequada. No caso da liberação da fosfoetanolamina sintética, pode se afirmar que não houve fundamentação suficiente que levasse à discussão sobre qual seria a melhor interpretação sobre a liberação do uso da pílula. 
Também, utilizando-se da ponderação de competências, é relativizada a ideia de última palavra definitiva, existindo meios de que os três Poderes exercitem suas competências ao mesmo tempo sem que haja, necessariamente, afronta às competências uns dos outros.

Percebe-se, assim, que a lógica de uma separação de poderes estática, em que a atuação de um Poder sempre interfira em grande medida na de outro, deve ser revista, de forma a equilibrar as relações entre estes e fazer com que as decisões possuam um maior embasamento e uma discussão que leve a maior concretização dos postulados constitucionais.

\section{A JUDICIALIZAÇÃ DO DIREITO À SAÚDE E O PRINCÍPIO DA SEPARAÇÃO DE PODERES NO BRASIL}

A liberação do uso da fosfoetanolamina sintética, com a edição da Lei n. 13.269/2016 ${ }^{2}$, e a sua consequente suspensão pelo Supremo Tribunal Federal, por meio da Ação Direta de Inconstitucionalidade n. 5.501, trouxeram à pauta, novamente, questões relativas à relação entre os Poderes Legislativo, Executivo e Judiciário.

A lei aprovada pelo Senado Federal e promulgada pela Presidência da República em 13 de abril de 2016, surgiu como uma resposta às diversas ações judiciais que vinham pleiteando o fornecimento da substância fosfoetanolamina sintética - conhecida como "pílula do câncer" - por parte da Universidade de São Paulo (USP).

Oportuno salientar, aqui, trecho do parecer da Procuradoria-Geral da República, no que se refere à quantidade de decisões determinando o fornecimento do "medicamento":

é patente a possibilidade do chamado efeito multiplicador, pois, segundo consta da inicial, foram estimadas 5.000 (cinco mil) decisões determinando o fornecimento da fosfoetanolamina pela Universidade, todas com fixação de multa diária pelo descumprimento. (STA828/SP, Rel. Ministro Ricardo Lewandowski, 2016, p. 17.)

Referidas decisões determinando o fornecimento da substância demonstram, além do mais, o cenário presente de judicialização do direito - especialmente do direito à saúde - onde, cada vez

\footnotetext{
${ }^{2}$ Art. 1o Esta Lei autoriza o uso da substância fosfoetanolamina sintética por pacientes diagnosticados com neoplasia maligna.

Art. 2 Poderão fazer uso da fosfoetanolamina sintética, por livre escolha, pacientes diagnosticados com neoplasia maligna, desde que observados os seguintes condicionantes:

I - laudo médico que comprove o diagnóstico;

II - assinatura de termo de consentimento e responsabilidade pelo paciente ou seu representante legal.

Parágrafo único. A opção pelo uso voluntário da fosfoetanolamina sintética não exclui o direito de acesso a outras modalidades terapêuticas.

Art. 3o Fica definido como de relevância pública o uso da fosfoetanolamina sintética nos termos desta Lei. Art. 4ํ Ficam permitidos a produção, manufatura, importação, distribuição, prescrição, dispensação, posse ou uso da fosfoetanolamina sintética, direcionados aos usos de que trata esta Lei, independentemente de registro sanitário, em caráter excepcional, enquanto estiverem em curso estudos clínicos acerca dessa substância. Parágrafo único. A produção, manufatura, importação, distribuição, prescrição e dispensação da fosfoetanolamina sintética somente são permitidas para agentes regularmente autorizados e licenciados pela autoridade sanitária competente.
} 
mais, o Judiciário é acionado na busca de sua realização. Mendes (2010, p. 483), quanto à efetivação do direito à saúde, esclarece que:

vê-se, pois, que os direitos fundamentais sociais foram acolhidos pela Constituição Federal de 1988 como autênticos direitos fundamentais. Não há dúvida - deixe-se claro - de que as demandas que buscam a efetivação de prestações de saúde devem ser resolvidas a partir da análise de nosso contexto constitucional e de suas peculiaridades.

No que se refere a esses direitos, Mendes (2010, p. 474) coloca que "encontraram uma receptividade sem precedentes no constitucionalismo pátrio, resultando, inclusive, na abertura de um capítulo especialmente dedicado aos direitos sociais no catálogo dos direitos e garantias fundamentais", restando clara a importância destinada aos direitos prestacionais em nossa jurisdição.

O papel do Poder Judiciário sofreu, dessa forma, significativa mudança no reconhecimento dos direitos sociais e, como colocado por Hachem (2014, p. 288), "pasaron a certificar la fundamentalidad de los derechos sociales (en especial los derechos a la educación y a la salud) y encaralos como derechos subjetivos, prontamente exigibles frente al Poder Judicial".

Dessa forma, diante da crescente demanda em matéria de direitos fundamentais sociais e do fenômeno da judicialização ${ }^{3}$, pode se dizer que essa, segundo Leal e Maas (2014, p. 26):

\begin{abstract}
consiste no resultado de um processo histórico, típico do constitucionalismo democrático, que tem por base, notadamente, múltiplos fatores, tais como a centralidade da Constituição e sua força normativa, associada a aspectos como o caráter principiológico, a supremacia e a dimensão objetiva dos direitos fundamentais [...]. Sua principal característica reside, portanto, num protagonismo do Judiciário, resultante de uma confluência de fatores que conduzem a uma transferência de decisões estratégicas sobre temas fundamentais (tradicionalmente reservadas à esfera política e deliberativa) a esse Poder, fazendo com que o direito seja, cada vez mais, um direito judicial, construído, no caso concreto, pelos magistrados.
\end{abstract}

Dessa forma, a dimensão conferida às decisões que determinam a efetivação do direito à saúde no Brasil permeia diversos questionamentos, dentre eles, a possibilidade de o Poder Judiciário intervir e determinar um facere aos demais Poderes, o protagonismo que decorre de dita intervenção e as barreiras estabelecidas pela reserva do possível ${ }^{4}$ e pelo princípio da separação de Poderes. É no último que se centra, no presente artigo, a análise da questão.

\footnotetext{
${ }^{3}$ A questão da judicialização é abordada, ainda, por Pimentel e Cecato (2016), como uma interpretação onde há a primazia dos direitos fundamentais, o que faz com que o papel do Poder Judiciário assuma novos contornos. Cf. PIMENTEL, Catarine Helena Limeira; CECATO, Maria Áurea Baroni. O papel político do Poder Judiciário na efetivação do direito à saúde do trabalhador: enfoque nas demandas acidentárias. Revista do Direito, Santa Cruz do Sul, v. 2, n. 49, maio 2016. ISSN 1982-9957. Disponível em:

https://online.unisc.br/seer/index.php/direito/article/view/8110/5128. Acesso em: 02/12/2016. doi:http://dx.doi.org/10.17058/rdunisc.v2i49.8110.

${ }^{4}$ Observa-se que a chamada "reserva do possível" se traduz na jurisprudência brasileira como a impossibilidade de exigir uma pretensão frente à escassez de recursos financeiros por parte do Estado, pouco se falando em razoabilidade do pedido, o que difere do sentido atribuído à expressão na decisão do Tribunal Constitucional Alemão (BverfGE n. 33, S. 333) - conhecida como Numerus Clausus -, como referido por Mânica (2010, p. 11): "ao decidir a questão o Tribunal Constitucional entendeu que o direito à prestação positiva - no caso aumento
} 
O princípio da separação de Poderes, invocado constantemente na jurisprudência do mais alto Tribunal brasileiro, tem como base a ideia de "freios e contrapesos" ${ }^{5}$ e de convivência harmônica entre os três Poderes. Dessa maneira, os Poderes tratam de negociar seus limites e de intercalar ações mais ativistas ou mais limitadas nas posturas que adotam (MENDES, 2014, p.165).

Contudo, como bem salientado por Mendes (2014, p. 165), "la Constitución no puede regular de manera estricta la división de poderes", trazendo níveis onde, em tese, deveria haver maior deferência entre os Poderes. De mesmo modo, o reconhecimento de direitos prestacionais e a possibilidade de exigi-los permite uma margem de dúvida quanto aos seus limites e ao que cabe a cada Poder definir. Hachem (2014, p. 297) ressalta, nesse diapasão, que:

cuando están involucrados, por otra parte, los deberes de protección y de promoción, que demandan prestaciones positivas, se torna más difícil exigirlos administrativamente cuando los delineamientos de su contenido no están trazados previamente por la Constitución o por la legislación. ¿Cuál sería, en estos casos, el contenido de los deberes estatales positivos, frente a la ausencia de previa delimitación normativa? Percíbase que no se está acá afirmando que es más difícil requerirse ante la Administración Pública la satisfacción de un derecho social que de un derecho de libertad, sino las funciones protectiva y prestacionalde cualquiera de estos derechos fundamentales, si comparadas con la función defensiva. (Grifos no original)

Frente à dificuldade entre compor a realização de direitos prestacionais e o princípio da separação de Poderes, Klatt (2015, p. 221) apresenta, justamente, a possibilidade de existir um controle judicial com diferentes níveis de intensidade:

ao invés de adotar um único modelo de controle judicial, forte ou fraco, os Tribunais devem adotar uma abordagem flexível que permita uma maior gama de níveis de intensidade de controle judicial. A escolha de uma determinada intensidade de controle depende das circunstâncias do caso em discussão, o qual, por sua vez, pode ser avaliado à luz de vários fatores.

É nesse sentido, então, que se pretende abordar a relação e o diálogo (não) estabelecido entre os Poderes do Estado, tomando como base as decisões relativas à fosfoetanolamina sintética e a aprovação da lei que autoriza sua comercialização sem registro na Agência Nacional de Vigilância Sanitária - ANVISA. Pretende-se tecer, também, comparações com o posicionamento adotado pela

do número de vagas na universidade - encontra-se sujeito à reserva do possível, no sentido daquilo que o indivíduo pode esperar, de maneira racional, da sociedade. Ou seja, a argumentação adotada refere-se à razoabilidade da pretensão". (Grifos no original)

${ }^{5}$ No tocante à Separação de Poderes e sua origem, Ferrajoli (2008, p. 339) coloca: "en el uso clásico del modelo deMontesquieu la división se refería a tres poderes: el Legislativo, el ejecutivo y el judicial; en el modelo de Locke se refería simplemente a dos poderes, el legislativo y el Ejecutivo. Se trata de modelos elaborados hace tres siglos con referencia a arreglos institucional es incomparablemente más simples que los de las actuales democracias constitucionales: en ese entonces las funciones del Estado eran poco más que la función penal y el mantenimiento del orden público al interior y la defensa militar al exterior. Respecto a estos arreglos la función principal de la división de poderes era la de diferenciar a los poderes del Estado, de tal manera que uno fuera el freno y el límite del otro; en particular, se trataba de garantizar la separación e independencia del poder monárquico de otra forma absoluto, de la función legislativa y de la función judicial". 
Corte brasileira na Suspensão de Tutela Antecipada 175, decisão paradigmática referente ao direito à saúde no Brasil.

\section{AS DECISÕES DO SUPREMO TRIBUNAL FEDERAL RELATIVAS À LIBERAÇÃO DA FOSFOETANOLAMINA E A LEGALIZAÇÃO DE SEU USO PELO CONGRESSO NACIONAL}

Com a divulgação da existência da "pílula do câncer", fornecida inicialmente de forma gratuita pela Universidade de São Paulo - USP, não demorou para surgirem diversas ações judiciais buscando a concessão de liminares que determinassem o fornecimento da substância por parte da Universidade. A "fosfo", como ficou conhecida, não possui, contudo, registro na Agência Nacional de Vigilância Sanitária e, mesmo assim, foi concedida em diversas ações judiciais.

O Ministro Luiz Edson Facchin, inclusive, proferiu decisão na liminar n. 5828 MC/SP, em 06/10/2015, limitando-se a analisar a presença da "fumaça do bom direito" e do "perigo na demora do provimento judicial", concedendo o fornecimento da fosfoetanolamina sintética. O Ministro entendeu, à época, que "a ausência de registro, no entanto, não implica, necessariamente, lesão à ordem pública, especialmente se considerando que o tema pende de análise por este Supremo Tribunal Federal" (BRASIL, STF, 2015).

Por outro lado, cabe observar que a liminar em questão contrariou o entendimento firmado pelo STF na Suspensão de Tutela Antecipada 175/Ceará, onde o Judiciário consolidou a possibilidade de intervenção em matéria de políticas públicas voltadas à promoção da saúde. $\mathrm{Na}$ ocasião, o Ministro Gilmar Mendes apontou algumas ressalvas a essa intervenção, estando, dentre elas, a falta de registro do fármaco na ANVISA ${ }^{6}$ :

não raro, busca-se, no Poder Judiciário, a condenação do Estado ao fornecimento de prestação de saúde não registrada na Agencia Nacional de Vigilância Sanitária (ANVISA). Como ficou claro nos depoimentos prestados na Audiência Pública, é vedado à Administração Pública fornecer fármaco que não possua registro na ANVISA. (BRASIL, STF, 2010).

Em razão das reiteradas condenações ao fornecimento do medicamento, a USP divulgou um comunicado afirmando que "não é uma indústria química ou farmacêutica" e que "não tem condições de produzir a substância em larga escala, para atender às centenas de liminares judiciais que recebeu nas últimas semanas" (USP, 2015) ${ }^{7}$. Ainda, ingressou com o pedido suspensão de tutela

\footnotetext{
${ }^{6}$ Necessário salientar, também, que em seu voto o Ministro Gilmar Ferreira Mendes refere que a falta de registro na ANVISA não obsta, por si só, a concessão do medicamento. Sendo assim, caso o medicamento pleiteado não possua registro na ANVISA, devem existir estudos ou o reconhecimento do fármaco em outros países e, ainda, a comprovação de que não exista outro medicamento eficaz, fornecido pelo SUS ou com registro na ANVISA, para o caso. Aduz ainda que "a participação nesses tratamentos rege-se pelas normas que regulam a pesquisa médica e, portanto, o Estado não pode ser condenado a fornecê-los" (BRASIL, STF, 2010, p. 21), ou seja, não cabe ao Judiciário determinar que um medicamento experimental seja fornecido pelo Estado, ou, no caso em análise, pela Universidade de São Paulo.

${ }^{7}$ comunicado emitido na data de 13 de outubro de 2015, após diversas decisões judiciais determinando o fornecimento da substância fosfoetanolamina. Disponível em: <http://www5.usp.br/99485/usp-divulgacomunicado-sobre-a-substancia-fosfoetanolamina>.
} 
antecipada que originou a Suspensão de Tutela Antecipada 828, sobre a qual cabem algumas considerações, sobre as quais se passa a discorrer na sequência.

\subsection{A Suspensão de Tutela Antecipada 828: o posicionamento inicial do Supremo Tribunal Federal quanto à concessão do fornecimento da fosfoetanolamina sintética}

A Suspensão de Tutela Antecipada 828, requerida pela Universidade de São Paulo - USP, centrou-se em discutir a possibilidade de fornecimento de uma substância não considerada medicamento. Em decisão monocrática, o Ministro Ricardo Lewandowski (2016, p.3), na condição de Ministro Presidente, citou que a USP "entende, ainda, que a 'fosfoetanolamina sintética' não é um medicamento, mas uma substância química que não passou por todas as etapas necessária para afastar os riscos à saúde das pessoas".

Acrescentou, ainda, citando o argumento utilizado pela USP, que:

a problemática do fornecimento da fosfoetanolamina sintética por parte da Universidade de São Paulo, enquanto objeto de pretensão jurisdicional, passa ao largo da jurisprudência do Supremo Tribunal Federal, que se tem dedicado a medicamentos às vezes caros demais para que o cidadão 0 alcance, às vezes não registrado na ANVISA mas registrado em instâncias internacionais, às vezes detentores de indicações clínicas alegadamente insuficientes para abarcar novas aplicações pretendidas por novos pacientes. (BRASIL, STF, 2016) (Grifos no original)

A decisão, em mesmos moldes das decisões envolvendo a prestação do direito à saúde, fez referência a diversos julgados pregressos da $\mathrm{Corte}^{8}$, evidenciando o entendimento que vem sendo consolidado quanto ao assunto ${ }^{9}$. Interessante registrar, nesse sentido, que esta auto-referência praticada pelo Supremo Tribunal Federal remete à crítica feita por Maus(2000, p. 192) ao que chama de "superego constitucional", salientando que o Tribunal Constitucional Alemão atua, muitas vezes, "menos como 'guardião da Constituição' do que como garantidor da própria história jurisprudencial, à qual se refere legitimamente de modo auto-referencial".

Interessante apontar que há uma preocupação em valer-se de argumentos técnicos, sendo referidos pareceres e notas publicadas por pesquisadores, como se extrai da nota publicada pela FIOCRUZ (BRASIL, STF, 2016), referindo que "pesquisadores da Fundação Oswaldo Cruz (Fiocruz) esclarecem que o medicamento [...] ainda necessita de uma série de estudos para ser considerado eficaz ou seguro para o uso clínico". Em mesma linha, são transcritas considerações do Instituto Nacional de Câncer - INCA, utilizadas nos autos da Ação Cautelar 4.081/SP (BRASIL, STF, 2015), destacando que "somente ao término dos estudos pré-clínicos e clínicos desta substância poder-se-á

\footnotetext{
${ }^{8}$ Como, por exemplo: Recurso Extraordinário 657.718, relatado pelo Ministro Marco Aurélio; Suspensão de Segurança 4.316/RO, Ministro Cezar Peluso; Suspensão de Liminar 815-AgR;

${ }^{9}$ Nesse sentido, cf. ZAGURSKI, Adriana Timoteo dos Santos; PAMPLONA, Danielle Anne. Judicialização da saúde e orçamento público.Revista do Direito, Santa Cruz do Sul, v. 1, n. 48, jan/abr. 2016. ISSN 1982-9957. Disponível em: https://online.unisc.br/seer/index.php/direito/article/view/6498/4665. Acesso em: 02/12/2016. doi: http://dx.doi.org/10.17058/rdunisc.v1i48.6498.
} 
elencar as possibilidades ou não de uso como medicação anticancerígena" e, ainda, que "anterior a isto, será antecipada e precipitada qualquer decisão terapêutica relacionada à Fosfoetanolamina".

Com base nos argumentos referidos, a decisão suspendeu a execução de todas as decisões que envolviam a determinação de concessão da substância pela USP proferidas em âmbito nacional. Entretanto, determinou a manutenção do fornecimento da fosfoetanolamina sintética até que esgotados os estoques da Universidade de São Paulo (BRASIL, STF, 2016).

Por fim, há que ser ressaltado trecho do voto do Ministro Lewandowski (2016, p. 12):

não desconheço que tramitou no Congresso Nacional projeto de lei que dispõe sobre o uso da "Fosfoetanolamina Sintética" por pacientes diagnosticados com neoplasia maligna. Tal projeto, depois de encaminhado pela Câmara dos Deputados, foi aprovado pelo Senado Federal no dia 22/3/2016, aguardando a apreciação da Presidência da República para a sua sanção ou veto.

Tal proposição, em que pese autorizar o uso da substância, não indica a quem caberia a responsabilidade pela sua produção e fornecimento.

A referência feita no voto deixa clara a existência de posicionamentos diversos quanto à possibilidade de autorização da fabricação e consumo da "pílula do câncer". A decisão do Supremo Tribunal Federal foi, por sua vez, proferida em 04 de abril de 2016, sendo a Lei 13.269/2016, que "autoriza o uso da fosfoetanolamina sintética por pacientes diagnosticados com neoplasia maligna" (BRASIL, 2016, http://www.planalto.gov.br/ccivil_03/_Ato2015-2018/2016/Lei/L13269.htm), publicada em 13 de abril de 2016, sendo o seu conteúdo objeto de análise no tópico que segue.

3.2. A aprovação da Lei 13.269/2016 (PLC 3/2016) no Senado Federal: o uso da fosfoetanolamina sintética e a ausência de registro na Agência Nacional de Vigilância Sanitária - ANVISA

De um lado, uma lei federal que autorizou o uso da substância fosfoetanolamina sintética; de outro, uma Ação Direita de Inconstitucionalidade, proposta pela Associação Médica Brasileira, que resultou na declaração de inconstitucionalidade da Lei 13.269/2016. Em um terceiro pólo, a Agência Nacional de Vigilância Sanitária - $\mathrm{ANVISA}^{10}$, autarquia sob regime especial, responsável pela regularização de fármacos no país.

A relação envolvendo a autorização da fosfoetanolamina englobou, a uma só vez, os Poderes Legislativo, Judiciário e Executivo, em posicionamentos diversos, estando, cada um, no exercício de

\footnotetext{
${ }^{10}$ Criada pela Lei no 9.782, de 26 de janeiro 1999, a Agência Nacional de Vigilância Sanitária (Anvisa) é uma autarquia sob regime especial, que tem sede e foro no Distrito Federal, e está presente em todo o território nacional por meio das coordenações de portos, aeroportos, fronteiras e recintos alfandegados.

Tem por finalidade institucional promover a proteção da saúde da população, por intermédio do controle sanitário da produção e consumo de produtos e serviços submetidos à vigilância sanitária, inclusive dos ambientes, dos processos, dos insumos e das tecnologias a eles relacionados, bem como o controle de portos, aeroportos, fronteiras e recintos alfandegados. Descrição retirada do sítio eletrônico da Anvisa $<$ http://portal.anvisa.gov.br/institucional>.
} 
suas funções típicas e atípicas. Emerge, dessa forma, a discussão sobre os limites da intervenção do Poder Judiciário e o princípio da separação de Poderes, destacado na ADI 5.501.

A lei 13.269/2016 trouxe a permissão de uso e, em seu artigo $4^{\circ}$, a possibilidade de "produção, manufatura, importação, distribuição, prescrição, dispensação, posse ou uso da fosfoetanolamina sintética" (BRASIL, 2016, http://www.planalto.gov.br/ccivil_03/_Ato20152018/2016/Lei/L13269.htm). Não obstante, deixou de fixar critérios no que concerne a quem caberia a responsabilidade por seu fornecimento e controle.

O principal objeto de divergência, também apontado no artigo $4^{\circ}$ da Lei, é a ausência de registro na ANVISA como condição para que a mesma seja fornecida. A lei teria, assim, invadido a competência do Poder Executivo, na figura da referida Agência, ignorando uma competência que lhe é atribuída pela Lei 9.782/1999, em seu parágrafo $7^{0}$ :

Art. $7^{\circ}$ Compete à Agência proceder à implementação e à execução do disposto nos incisos II a VII do art. $2^{\circ}$ desta Lei, devendo:

I - coordenar o Sistema Nacional de Vigilância Sanitária;

II - fomentar e realizar estudos e pesquisas no âmbito de suas atribuições;

III - estabelecer normas, propor, acompanhar e executar as políticas, as diretrizes e as ações de vigilância sanitária;

IV - estabelecer normas e padrões sobre limites de contaminantes, resíduos tóxicos, desinfetantes, metais pesados e outros que envolvam risco à saúde;

[...]

VII - autorizar o funcionamento de empresas de fabricação, distribuição e importação dos produtos mencionados no art. 80 desta Lei e de comercialização de medicamentos;

VIII - anuir com a importação e exportação dos produtos mencionados no art. $8^{\circ}$ desta Lei;

IX - conceder registros de produtos, segundo as normas de sua área de atuação;

$[\ldots]$

XXII - coordenar e executar o controle da qualidade de bens e produtos relacionados no art. $8^{\circ}$ desta Lei, por meio de análises previstas na legislação sanitária, ou de programas especiais de monitoramento da qualidade em $\quad$ saúde; ${ }^{11}$ (BRASIL, http://www.planalto.gov.br/ccivil_03/leis/L9782.htm)

\footnotetext{
${ }^{11}$ Art. 8o Incumbe à Agência, respeitada a legislação em vigor, regulamentar, controlar e fiscalizar os produtos e serviços que envolvam risco à saúde pública.

$\S 1$ 을 Consideram-se bens e produtos submetidos ao controle e fiscalização sanitária pela Agência:

I - medicamentos de uso humano, suas substâncias ativas e demais insumos, processos e tecnologias;

II - alimentos, inclusive bebidas, águas envasadas, seus insumos, suas embalagens, aditivos alimentares, limites

de contaminantes orgânicos, resíduos de agrotóxicos e de medicamentos veterinários;

III - cosméticos, produtos de higiene pessoal e perfumes;

IV - saneantes destinados à higienização, desinfecção ou desinfestação em ambientes domiciliares, hospitalares e coletivos;

$V$ - conjuntos, reagentes e insumos destinados a diagnóstico;

$\mathrm{VI}$ - equipamentos e materiais médico-hospitalares, odontológicos e hemoterápicos e de diagnóstico

laboratorial e por imagem;

VII - imunobiológicos e suas substâncias ativas, sangue e hemoderivados;

VIII - órgãos, tecidos humanos e veterinários para uso em transplantes ou reconstituições;

IX - radioisótopos para uso diagnóstico in vivo e radiofármacos e produtos radioativos utilizados em diagnóstico e terapia;

X - cigarros, cigarrilhas, charutos e qualquer outro produto fumígero, derivado ou não do tabaco;
} 
Faz-se necessário analisar, então, os argumentos levantados no voto do Ministro Luís Roberto Barroso, na ADI 5.501, que determinou a suspensão dos efeitos da lei que autorizou o uso da fosfoetanolamina sintética e como foi tratada a questão da separação de poderes na decisão.

\subsection{A Ação Direta de Inconstitucionalidade 5.501: a decisão que suspendeu a eficácia da Lei 13.269/2016 e o uso da "pílula do câncer"}

A Associação Médica Brasileira sustentou, na ADI 5.501, que a autorização de uso da "pílula do câncer", sem respaldo de estudos que comprovem a sua eficácia e a ausência de riscos advindos de seu consumo, violaria uma série de dispositivos constitucionais ${ }^{12}$. A medida cautelar buscando a suspensão da Lei 13.269/2016 pautou-se nessa questão, entendendo que houve desrespeito ao princípio da separação de Poderes, vez que

há na hipótese, igualmente, violação à reserva de administração. Ao autorizar o uso da fosfoetanolamina sintética sem cumprimento das exigências legais de realização de testes clínicos e de registro sanitário, o Poder Legislativo substituiu o juízo essencialmente técnico da Anvisa por um juízo político, interferindo de forma indevida em procedimento de natureza tipicamente administrativa.

O Poder Legislativo teria interferido em conteúdo que se encontra na chamada "reserva de administração", ou seja, teria desconsiderado um conteúdo constitucional que determinava a necessidade de prévio registro na ANVISA para a distribuição e uso de medicamentos. Canotilho (2003, p. 739), por sua vez, conceitua a reserva de administração como "um núcleo funcional de administração 'resistente' à lei, ou seja, um domínio reservado à administração contra as ingerências do Parlamento".

Importa observar, também, que não ocorreu uma hipótese de omissão quanto à regulação da substância, pois essa ainda encontrava-se em fase de testes, não havendo qualquer justificativa que autorizasse o Poder Legislativo a suprimir a regulação existente. Não estaria configurada a possibilidade de atuação de outro Poder para suprir a lacuna existente, na perspectiva indicada porMonteiro (2010, p. 168), de que "se um dos Poderes não exerce o seu papel, compete aos outros suprimir sua falta".

Barroso (BRASIL, STF, 2016) enfatiza, ainda, que:

XI - quaisquer produtos que envolvam a possibilidade de risco à saúde, obtidos por engenharia genética, por outro procedimento ou ainda submetidos a fontes de radiação.

12 É parte do voto do Ministro Luís Roberto Barroso (BRASIL, STF, 2016, p. 3): "Segundo alega,seriam violados os direitos fundamentais à saúde (CF/1988, arts. $6^{\circ}$ e 196), à segurança(CF/1988, $5^{\circ}$, caput) e à vida $\left(C F / 1988,5^{\circ}\right.$, caput), bem como o princípio da dignidade da pessoa humana (CF/1988, art. $1^{\circ}$, III). Além disso, em relação a dispositivos específicos da lei, aponta afronta (i) ao dever de promoção do direito à saúde (CF/1988, art. 196), pela oferta de substância independente de prescrição médica (apenas mediante laudo médico), e (ii) ao princípio da estrita legalidade aplicável à Administração Pública (CF/1988, art. 37), em razão da dispensa de registro sanitário para uso da substância". 
esse domínio legítimo de atuação administrativa da Anvisa, balizado pela lei, deve ser respeitado pelas diferentes instâncias de controle, inclusive pelo Poder Legislativo. Trata-se de uma exigência que decorre logicamente da separação de poderes. Daí porque a Lei no 13.269/2016, ao substituir uma escolha técnica e procedimental da Agência por uma decisão política do Legislador, interferiu de forma ilegítima no funcionamento da Administração Pública, em afronta à reserva de administração e à separação de poderes.

O procedimento de registro sanitário perante a ANVISA não seria exigido por mera burocracia e sim em razão de tratar-se de registro e controle essencial à proteção ao direito à saúde, tanto que a competência para tal foi atribuída por lei à autarquia (BRASIL, STF, 2016). O Ministro Luís Roberto Barroso (2016, p. 9) entendeu, assim, que, na autorização realizada por lei pelo Poder Legislativo, "há evidente violação ao direito à saúde e, ainda, ao princípio da separação de Poderes".

Interessante registrar que os argumentos apresentados pela Câmara dos Deputados e pelo Sendo Federal, ao justificarem a edição da lei que autorizou o uso da substância, possuem cunho estritamente político, pautando a autorização em uma desmedida busca da sociedade pelo medicamento, não considerando os riscos que poderiam ser gerados com essa autorização, como se extrai de trecho do voto:

a Câmara dos Deputados afirmou que os objetivos principais da lei foram proteger "o direito à vida, a supremacia da dignidade humana, o direito à saúde, o direito à liberdade em toda a sua amplitude e o direito de lutar pela própria vida inerente à natureza humana". Segundo alegou, a lei foi editada como forma de (i) "proteger a saúde de milhares de pacientes que já faziam uso da substância"; (ii) "permitir o acesso legalizado à substância a ser produzida com a observância das normas que garantam sua qualidade e segurança"; e (iii) "garantir o direito de lutar pela própria vida, mediante o reconhecimento da autonomia da vontade, aos pacientes diagnosticados com neoplasia maligna e que não dispunham de alternativas terapêuticas autorizadas pelo Poder Público". 6. Já o Senado argumentou que a lei não pode ser considerada inconstitucional, uma vez que "veio atender o legítimo anseio de milhares de enfermos que lutam por suas vidas e para os quais não há mais tratamento conhecido, escutar as angustias de famílias que acompanham seus entes queridos e para as quais nenhuma possibilidade de cura pode ser desprezada". Ademais, argumentou haver diversos trabalhos científicos publicados em revistas especializadas e numerosos relatos clínicos de pacientes que atestariam a eficácia do medicamento no combate ao câncer. Por fim, a Presidência da República afirmou ser "precipitado falar em risco à vida ou integridade física de pessoas ou mesmo à dignidade da pessoa humana", pois, "ao contrário, o objetivo da Lei na 13.269, de 2016 é a proteção do direito à vida, valor central do ordenamento jurídico, considerado em um sentido amplo, abarcando não apenas a existência física mas também o direito à vida digna.". (BRASIL, STF, 2016, p. 5) (Grifos no original)

Foi, portanto, sob o fundamento de inexistência de comprovação da eficácia e dos possíveis riscos da liberação e uso da substância fosfoetanolamina sintética que restou suspensa cautelarmente e de forma integral a Lei 13.269/2016. Exerceu, assim, o Supremo Tribunal Federal o controle abstrato de constitucionalidade, competência que Ihe é atribuída pela Constituição Federal de 1988.

Revista do Direito [ISSN 1982-9957]. Santa Cruz do Sul, v. 3, n. 50, p. 34-52, set./dez. 2016. https://online.unisc.br/seer/index.php/direito/index 
Interessante considerar, neste ponto, a consideração de Bonavides (2002, p. 77) no que diz respeito ao controle de atos legislativos:

partiu Marshall para uma proposição evidente e incontestável: ou a Constituição controla todo ato legislativo que a contrarie, ou o legislativo, por um ato ordinário, poderá modificar a Constituição. A Constituição é lei superior e suprema, que se não pode alterar por vias or-dinárias ou entra na mesma esfera e categoria dos atos legislativos ordinários, sendo como

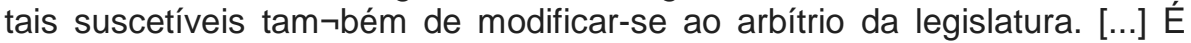
dever do Poder Judiciário declarar o direito. De modo que se uma lei colide com a Constituição, se ambas, a lei e a Constituição, se aplicam a uma determinada causa, o tri-bunal há de decidir essa causa, ou de conformidade com a lei, desrespeitando a Constituição, ou de acordo com a Constituição, ignorando a lei; em suma, à Corte compe-te determinar qual dessas regras antagônicas se aplica à espécie litigiosa, pois nisso consiste a essência mesma do dever judiciário.

Pode-se perceber, por todo o exposto, que não ocorre um diálogo institucional ${ }^{13}$ entre os Poderes do Estado brasileiro, pois ainda que existente uma lei que auferisse a capacidade da ANVISA em controlar medicamentos e substâncias e uma decisão suspendendo as liminares concedidas judicialmente, o Poder Legislativo votou e aprovou, com posterior sanção presidencial, uma lei que ia de encontro ao que os Poderes Executivo e Judiciário já alertavam.

Ainda, o próprio Poder Executivo contrariou e suprimiu a capacidade regulatória da Agência Nacional de Vigilância Sanitária ao sancionar, sem vetos, a Lei 13.269/2016, restando ignorada a norma que tratava da imprescindibilidade de registro de fármaco pela ANVISA.

Assim, o princípio da separação de Poderes - invocado como argumento para a suspensão da lei - e a ideia de harmonia entre Poderes não se mostraram, na prática, eficientes. Busca-se, então, uma melhor compreensão de como conciliar e melhor adequar ao caso concreto a separação de Poderes, a partir da perspectiva de uma noção de "diálogo institucional".

\section{A SEPARAÇÃO DE PODERES COMO PRINCÍPIO CONSTITUCIONAL, E NÃO COMO REGRA: PONDERAÇÃO DE COMPETÊNCIAS, E NÃO LÓGICA DO “TUDO OU NADA"}

Os direitos prestacionais ${ }^{14}$, enquanto direitos positivos, demandam dos Poderes ações que garantam sua concretização. Vinculam o Poder Executivo na efetivação de políticas públicas e de

\footnotetext{
${ }^{13}$ Quanto a teoria do "diálogo institucional", Mendes (2008, p. 15) conceitua: basicamente, essas teorias defendem que não deve haver competição ou conflito pela última palavra, mas um diálogo permanente e cooperativo entre instituições que, por meio de suas singulares expertises e contextos decisórios, são parceiros na busca do melhor significado constitucional. Assim, não haveria prioridade, hierarquia ou verticalidade entre instituições lutando pelo monopólio decisório sobre direitos fundamentais. Haveria, ao contrário, uma cadeia de contribuições horizontais que ajudariam a refinar, com a passagem do tempo, boas respostas para questões coletivas. Separação de poderes, nesse sentido, envolveria circularidade e complementaridade infinitas.

${ }^{14}$ Para Alexy (2012, p. 202), os direitos prestacionais se dividem em direitos a prestações fáticas e normativas, o qual refere que "quando se fala em 'direitos a prestações' faz-se referência, em geral, a ações positivas fáticas. Tais direitos, que dizem respeito a prestações fáticas que, em sua essência, poderiam ser também realizadas por particulares, devem ser designados como direitos a prestações em sentido estrito. Mas, além de direitos a prestações fáticas, pode-se também falar de prestações normativas. Nesse caso, também os direitos
} 
meios que assegurem sua realização, o Poder Legislativo na criação dessas políticas e de leis que Ihes complementem e o Poder Judiciário em seu controle, buscando que a Constituição Federal seja colocada em prática.

Dessa forma, diante do caráter de exigibilidade que ostentam, pode se afirmar que os direitos fundamentais sociais demandam ações ${ }^{15}$ que busquem a sua máxima concretização, como bem coloca Queiroz (2006, p. 16):

de um ponto de vista estrutural, os direitos económicos (sic), sociais e culturais ou, genericamente, os direitos fundamentais sociais, constituem obrigações de prestação positivas cuja satisfação consiste num facere, uma "acção (sic) positiva" a cargo dos poderes públicos. (grifos no original)

Sendo assim, a constitucionalização desses direitos tem o condão de "autorizar" o Poder Judiciário a intervir em nome de uma proteção do conteúdo constitucional, o que faz com que, como bem sintetiza Michelman (2005, p. 134), "o problema da constitucionalização de direitos sociais se torna principalmente, se não exclusivamente, uma questão de separação dos Poderes". Até onde cabe a cada Poder decidir torna-se uma questão de competência.

Assim, as discussões envolvendo o princípio da separação de Poderes encontram-se, inevitavelmente, na questão relativa a qual órgão detém qual competência. Em decorrência disto, a maior dificuldade, quando estão em jogo direitos que exigem prestações positivas, é a determinação da competência de cada um desses Poderes (KLATT, 2015, p. 223)

Isto porque, diferentemente da função de defesa presente nos direitos de primeira dimensão, a função prestacional dos direitos fundamentais sociais coloca em xeque a divisão de Poderes:

emerge, en este escenario, la cuestión atinente a la separación de los poderes y al principio democrático. Es plenamente compatible con dichos postulados la exigibilidad de la dimensión negativa de los derechos fundamentales, una vez que no hay dudas de que intervenciones indebidas en el ámbito de estos derechos son prohibidas constitucionalmente. Ocurre, sin embargo, que en relación con la dimensión positiva es, en alguna medida, más cuestionable la aceptación de que el Poder Ejecutivo o el Poder Judicial puedan realizar elecciones políticas cuanto al contenido, extensión y alcance de estos derechos, los cuales, por regla general, deberían ser delimitados por el Poder Legislativo en el campo del debate público y democrático, legitimado por la población para la toma de decisiones políticas.(HACHEM, 2014, p. 297)

Parte-se do pressuposto de uma divisão de funções oriunda da separação de Poderes, a qual acaba por mostrar-se incompatível com a realização de direitos prestacionais de forma plena, sem que seu conteúdo seja, portanto, questionado.

a ações positivas normativas adquirem o caráter de direitos a prestações. Eles devem ser designados como direitos a prestações em sentido amplo".

${ }^{15}$ Necessária referência a Sarlet $(2003$, p. 53) no que toca aos direitos sociais, quando este afirma que "não englobam apenas direitos de cunho positivo, mas também as assim denominadas 'liberdades sociais', do que dão conta os exemplos da liberdade de sindicalização, do direito de greve, bem como o do reconhecimento de direitos fundamentais aos trabalhadores, tais como o direito a férias e ao repouso semanal remunerado". 
Buscando enfrentar teoricamente o problema, Klatt (2015, p. 235) apresenta uma proposta de controle judicial pautado em diferente níveis de deferência, onde

são questões decisivas, então, saber como poderíamos ter flexibilidade em graus de deferência e, ao mesmo tempo, assegurar a desejada previsibilidade. A resposta a isso depende da reconstrução do controle judicial como um conflito de competências que pode ser resolvido a partir de um procedimento de ponderação. (Grifos no original)

Diante de um conflito de competências, o caminho traçado seria, então, a sua ponderação, compreendendo-se referidas competências como princípios que devem ser realizados na maior medida possível, como mandamentos de otimização, diante das possibilidades que se apresentarem (KLATT, 2015, p. 236). Klatt (2015, p. 237) esclarece que "o problema do controle judicial não é uma questão excludente do tipo 'ou um ou outro': é uma questão de grau".

Não se trata, pois, de abdicar do controle judicial ou mesmo de tornar o Supremo Tribunal Federal o único detentor da última palavra da jurisdição constitucional brasileira, mas sim de perceber, diante do caso concreto, até onde deve exercer a sua competência. Para tanto, é imprescindível que haja uma abertura à superação de decisões emanadas pelo Poder Judiciário, existindo um "diálogo institucional" onde restem claros os motivos pelos quais uma nova interpretação seria mais correta àquele caso.

Nesse tocante, o Ministro Luís Roberto Barroso (BRASIL, STF, 2015), em voto proferido na Ação Direita de Inconstitucionalidade 5.105, bem referiu acerca das possibilidades de diálogo institucional ${ }^{16}$ e de superação da jurisprudência do mais alto Tribunal brasileiro:

a terceira e última forma de diálogo institucional, a meu ver, é a superação da jurisprudência, que é precisamente a discussão que nós estamos travando aqui. A superação da jurisprudência pode se dar mediante emenda

\footnotetext{
${ }^{16}$ O Ministro (BRASIL, STF, 2015) apresenta três formas de diálogo institucional. São as primeiras: "os diálogos institucionais podem se concretizar por meio de diferentes comportamentos. Do ponto de vista do Supremo Tribunal Federal, eu pessoalmente tenho procurado fomentar o chamado apelo ao legislador, que é uma primeira versão dessa ideia de diálogos institucionais. Verificando que alguma matéria é malversada, mas que a correção depende de atuação do Poder Legislativo, o Supremo Tribunal Federal se manifesta neste sentido, dando ciência ao Legislativo de que há uma mudança a ser feita. Eu mesmo votei nesse sentido na questão relativa à perda de mandato. Eu entendo que está dito na Constituição com todas as letras, embora seja ruim, que a perda do mandato mesmo depois de condenação depende de deliberação da Casa Legislativa. É péssimo uma decisão do Supremo estar sujeita à deliberação da Casa Legislativa, mas é o que está dito na Constituição. Assim, ao votar no caso Ivo Cassol, afirmei expressamente que achava muito ruim essa solução e fiz um apelo a que o Congresso modificasse esse regramento. Evidentemente, não pelo meu apelo, porque eu não tenho essa pretensão, mas a verdade é que o Senado Federal já aprovou essa modificação, que agora depende de aprovação pela Câmara dos Deputados. Portanto, uma primeira vertente do diálogo institucional é o apelo ao legislador". " A segunda vertente do diálogo institucional, a meu ver, é a devolução da matéria pelo Supremo ao Poder Legislativo. Foi, por exemplo, a proposta que eu mesmo fiz no caso de desaposentação, em que eu disse: não há lei tratando dessa matéria, eu proponho a seguinte solução para viger daqui a cento e oitenta dias, a menos que o Congresso proveja a respeito, como de sua competência. Essa é tipicamente uma hipótese de diálogo institucional. Em vez de dar a última palavra, o Supremo estimula, incentiva o Congresso a prover sobre uma matéria".
} 
constitucional aprovada pelo Congresso, no exercício do poder constituinte derivado, ou mediante a aprovação de uma lei.Devo dizer que a superação de jurisprudência, como é o caso aqui, por aprovação de lei pressupõe que exista mais de uma interpretação constitucional possível e válida para que o Congresso possa optar por uma diferente daquela que o Supremo optou. Assim, a regra geral é que superação de jurisprudência se faça por emenda à Constituição, como o Congresso Nacional fez em relação: (i) à taxa municipal de iluminação pública; (ii) à progressividade das alíquotas do IPTU; (iii) à cobrança de contribuição previdenciária de inativos; e (iv) à questão do número de vereadores.

Aparece, assim, no discurso jurisprudencial do Supremo Tribunal Federal brasileiro, o argumento de que a sua "última palavra" é provisória e pode ser revista - argumento que, por muitas vezes, é utilizado contra criticas à legitimidade do Judiciário -, com a ressalva de que haja outra interpretação constitucional possível. Inegavelmente, a questão será desenvolvida e revista por meio da argumentação.

A citada possibilidade, frisa-se, não guarda semelhança com caso da edição da Lei 13.269/2016, autorizando o uso da fosfoetanolamina sintética, pois aquela sequer apresentou elementos que superassem os já firmados, restringindo-se a regular uma substância (e considerá-la um medicamento) ainda que ausentes os pressupostos mínimos para tal. Seria necessária a demonstração, de ordem argumentativa e teórica, de que a interpretação realizada pelo Congresso Nacional - possibilitando a utilização da substância fosfoetanolamina sintética - seria a mais adequada e também encontraria respaldo em nossa Constituição Federal.

Nesse sentido, Mendes (2014, p. 166) aponta com clareza a necessidade de argumentação para que se supere a ideia de uma rígida divisão de Poderes, que não permita uma revisão do já decidido:

el grado de resistencia de la última palabra provisional, tal como estableciéramos antes, está sujeto a este tipo de variaciones. Si todo esto es cierto, la teoría normativa enfrenta el desafío de evitar ligar las instituciones a un esquema rígido de división de poderes (o a métodos hermenéuticos estrictos) y por el contrario debe asegurarse de que los principios reactores de este tipo de oscilaciones sean permeables a los buenos argumentos.

Para que essa abertura ocorra de fato, contudo, é primordial compreender que a ponderação de competências "permite conciliar a obrigação constitucional de transformar direitos positivos em realidade concreta, sem desrespeitar a autoridade do Legislativo e do Executivo"(KLATT, 2015, p. 237). Os níveis de intervenção variam, assim, diante da qualidade da decisão e fazem com que seja considerada mais séria qualquer interferência que ocorra na primeira (KLATT, 2015, p. 242).

Estabelece-se, dessa maneira, uma relação de deferência entre os Poderes e as decisões tomadas por estes, não se confundindo referida deferência com a sujeição de um Poder aos demais. Nessa linha, Estay (2015, p. 372), sustenta que o conceito de deferência ou auto-restrição

por una parte, implica "que los poderes públicos se deben una actitud remanente y recíproca de respeto y cortesía" y, por otra, supone "de carda órgano del Estado el reconocimiento y respeto de las esferas 
competenciales en que las autoridades tienen el derecho a tomar decisiones con relativa autonomía".

Dessa forma, pode-se afirmar que todo e qualquer controle judicial estará configurado como uma intervenção, pois há uma revisão e modificação das premissas anteriormente decididas. A questão, então, como elucida Klatt (2015, p. 241), "não é se há ou não interferência, mas sim qual é o peso dessa interferência".

Outrossim, está em jogo o nível da interferência (leve, moderado ou excessivo), permeando o alto grau de deferência e a supremacia judicial, havendo "uma escala que vai do mero envolvimento, passa pelo envolvimento razoável e vai até um envolvimento significativo do Tribunal" (KLATT, 2015, p. 243).

Sendo assim, a separação de Poderes, enquanto princípio que é, deve ser encarada em uma perspectiva que permita a ponderação entre as competências, fugindo-se da noção de funções estáticas, adequando cada atuação diante do caso concreto, dos direitos em análise e da qualidade e elementos apresentados pelas decisões envolvidas.

\section{CONSIDERAÇÕES FINAIS}

Os debates acerca da liberação de uso da substância fosfoetanolamina sintética não se resumem, como exposto, apenas ao fato de ser ou não permitido seu uso sem o devido registro na Agência Nacional de Vigilância Sanitária - ANVISA. O caminho percorrido entre Supremo Tribunal Federal, Congresso Nacional e, novamente, Supremo Tribunal Federal demonstra a ausência de um diálogo institucional e a falta de fundamentação entre diferentes decisões - opostas, inclusive - quanto ao mesmo objeto.

Os direitos prestacionais nos trazem, então, uma dificuldade: como proteger seu conteúdo sem que haja um controle excessivo por parte dos Tribunais? É premente a superação da clássica divisão de Poderes como algo imutável e inflexível, para que haja, em nossa prática jurisprudencial, a real efetivação dos direitos constitucionalmente consagrados e também de uma lógica divisão de competências.

Diante dessa perspectiva, buscar na ponderação o aparato necessário para garantir esta concretização e uma deferência entre os Poderes Executivo, Legislativo e Judiciário mostra-se uma alternativa viável. Para tanto, é necessário compreender as competência como princípios que devem ser realizados na maior medida possível, sem uma mera aplicação de um ou de outro àquele caso.

Portanto, a abertura ao diálogo constitucional e à utilização de técnicas argumentativas são partes de um processo que busca adequar as decisões às possibilidades que o caso concreto apresenta. É possível, dessa forma, perceber, na jurisdição constitucional, uma última palavra provisória que, desde que demonstrada outra interpretação cabível, pode ser revista por algum dos outros Poderes estatais.

Enfim, a flexibilização de uma teoria de divisão de Poderes tem o condão de fazer com que uma decisão comporte, além da realização de direitos fundamentais sociais, a concretização 
de postulados materiais, dentre eles, uma correta aplicação do princípio da separação de Poderes, a partir de uma lógica de deferência entre eles. Assim, para além do discurso de abertura constitucional, é preciso fazer-se com que o princípio da separação de Poderes não seja invocado apenas como entrave às decisões judiciais, mas sim como forma de torná-las mais legítimas e efetivas.

\section{REFERÊNCIAS}

$<$ http://portal.anvisa.gov.br/institucional>.

<http://www5.usp.br/99485/usp-divulga-comunicado-sobre-a-substancia-fosfoetanolamina> .

ALEXY, Robert. Teoria Geral dos Direitos Fundamentais. 2º ed. São Paulo: Malheiros, 2012.

BONAVIDES, Paulo. Curso de Direito Constitucional. 12ª ed. rev. e atual. São Paulo: Malheiros. 2002.

BRASIL. Lei n. ${ }^{\circ}$ 13.269/2016, de 13 de abril de 2016. Diário Oficial [da] República Federativa do Brasil, Brasília, DF, 14 abr. 2016; Disponível em: <http://www.planalto.gov.br/ccivil_03/_Ato20152018/2016/Lei/L13269.htm>. Acesso em: 02 ago. 2016.

BRASIL. Lei n. 9 9.782/1999, de 26 de janeiro de 1999. Diário Oficial [da] República Federativa do Brasil, Brasília, DF, 27 jan. 1999; Disponível em: <http://www.planalto.gov.br/ccivil_03/leis/L9782.htm>. Acesso em: 02 ago. 2016.

BRASIL. Supremo Tribunal Federal. Ação Direta de Inconstitucionalidade n. ${ }^{0}$ 5.501. Rel. Ministro Marco Aurélio. Julgado em 09 ago. 2016. Disponível em: <http://www.stf.jus.br>. Acesso em: 03 ago. 2016.

BRASIL. Supremo Tribunal Federal. Ação Direta de Inconstitucionalidade n. ${ }^{0} 5.105$. Rel. Ministro Luiz Fux. Julgado em 01 out. 2015. Disponível em: <http://www.stf.jus.br>. Acesso em: 03 ago. 2016.

BRASIL. Supremo Tribunal Federal. Agravo na Suspensão de Tutela Antecipada $n^{\circ} 175$, Rel. Ministro Gilmar Ferreira Mendes. DJ, 30/04/2010. Disponível em <http://www.stf.jus.br>. Acesso em: 02 ago. 2016.

BRASIL. Supremo Tribunal Federal. Medida cautelar n. 5.828/SP. Rel. Ministro Luiz Edson Facchin. Julgado em 06 out. 2015. Disponível em: <http://www.stf.jus.br>. Acesso em: 03 ago. 2016.

BRASIL. Supremo Tribunal Federal. Suspensão de Tutela Antecipada n. ${ }^{\circ} 828$, Rel. Ministro Ricardo Lewandowisk. DJ, 06/04/2016. Disponível em <http://www.stf.jus.br>. Acesso em: 10 maio 2016.

CANOTILHO, J. J. Gomes. Direito constitucional e teoria da constituição. 7. ed. Coimbra: Almedina, 2003. 
ESTAY, José Ignacio Martinez. Auto Restricción, Deferencia y Margen de Apreciación. Breve análisis de sus orígenes y de su desarrollo. In: Estudios Constitucionales: Revista del Centro de Estudios Constitucionales. 2014.

FERRAJOLI, Luigi. La esfera de lo indecidible y la división de poderes.In: Estudios Constitucionales: Revista del Centro de Estudios Constitucionales, Ano 6, n. ${ }^{\circ}$ 1, 2008.

HACHEM, Daniel Wunder. Derechos fundamentales económicos y sociales y la responsabilidad del Estado por omisión. In: Estudios Constitucionales: Revista del Centro de Estudios Constitucionales, Ano 12, no. 1, 2014.

KLATT, Matthias. Direitos a prestações positivas: quem deve decidir? Controle judicial ponderado. In: ALEXY, Robert; BAEZ, Narciso Leandro Xavier; SILVA, Rogério Luiz Nery da (org.). Dignidade humana, direitos sociais e não-positivismo inclusivo. Trad. Carlos Luiz Strapazzon. Florianópolis, 2015. p. 215-266.

LEAL, Mônia Clarissa Hennig; MAAS, Rosana Helena. O Amicus Curiae e o Supremo Tribunal Federal: fundamentos teóricos e análise crítica. Curitiba: Multideia, 2014.

MÂNICA, Fernando Borges. Teoria da Reserva do Possível: direitos fundamentais a prestações e a intervenção do Poder Judiciário na implementação de políticas públicas. Salvador: Revista Eletrônica sobre a Reforma do Estado, n. 21, mar./abr./maio 2010.

MAUS, Ingeborg. Justizalsgesellschaftliche Uber-Ich - Zur FuntionvonRechtpreschungin der 'vaterlosen' Gesellschaft, in Werner Faulstich e Gunter Grimm (orgs.): Sturz der Goetter. Frankfurt am Main: Suhkamp, 1989, 1a ed. Tradução de Matonio Mont'Alverne Barreto Lima e Paulo Antonio de Menezes Albuquerque:O Judiciário como superego da sociedade - sobre o papel da atividade jurisprudencial na "sociedade órfã".

MENDES, Conrado Hübner. Direitos fundamentais, separação de poderes e deliberação. 2008. 219 f. Tese: Doutorado em Ciência Política. Faculdade de Filosofia, Letras e Ciências Humanas, Universidade de São Paulo, 2008.

MENDES, Conrado Hübner. Una división de poderes deliberativa: entre el diálogo y la última palabra. In: GARGARELLA, Roberto (Comp.). Por una justicia dialógica: el poder judicial como promotor de la deliberación democrática. $1^{\text {a }}$ ed. Buenos Aires: Siglo Veintiuno Editores, 2014.

MENDES, Gilmar Ferreira. Direitos Fundamentais e Controle de Constitucionalidade: Estudos de direito constitucional (Série EDB). 4ª ed. São Paulo: Editora Saraiva, 2012.

MICHELMAN, Frank I.. A Constituição, os direitos sociais e a justificativa política liberal. In: SARLET, I. W. (Org.). Jurisdição e Direitos Fundamentais. Porto Alegre: Livraria do Advogado editora, 2005. p. 131-155. 
MONTEIRO, Juliano Ralo. Ativismo judicial: um caminho para a concretização dos direitos fundamentais. In JÚNIOR, José Levi Mello do Amaral. Estado de direito e ativismo judicial. São Paulo: Quartier Latin do Brasil, 2010.

PIMENTEL, Catarine Helena Limeira; CECATO, Maria Áurea Baroni. O papel político do Poder Judiciário na efetivação do direito à saúde do trabalhador: enfoque nas demandas acidentárias. Revista do Direito, Santa Cruz do Sul, v. 2, n. 49, maio 2016. ISSN 1982-9957. Disponível em: https://online.unisc.br/seer/index.php/direito/article/view/8110/5128. Acesso em: 02/12/2016. doi:http://dx.doi.org/10.17058/rdunisc.v2i49.8110.

QUEIROZ, Cristina. O princípio não reversibilidade dos direitos fundamentais sociais: princípios dogmáticos e prática jurisprudencial. Lisboa: Coimbra, 2006.

SARLET, Ingo Wolfgang. A eficácia dos direitos fundamentais. 3. ed. Porto Alegre: Livraria do Advogado, 2003.

ZAGURSKI, Adriana Timoteo dos Santos; PAMPLONA, Danielle Anne. Judicialização da saúde e orçamento público. Revista do Direito, Santa Cruz do Sul, v. 1, n. 48, jan/abr. 2016. ISSN 1982-9957. Disponível em: https://online.unisc.br/seer/index.php/direito/article/view/6498/4665. Acesso em: 02/12/2016. doi: http://dx.doi.org/10.17058/rdunisc.v1i48.6498

\section{COMO CITAR ESSE DOCUMENTO:}

HENNIG LEAL, Mônia Clarissa; MORAES, Maria Valentina de. O princípio da separação de poderes e a ponderação de competências: uma análise crítica a partir da decisão sobre a fosfoetanolamina. Revista do Direito, Santa Cruz do Sul, v. 3, n. 50, p. 34-52, set. 2016. ISSN 1982-9957. Disponível em: $<$ https://online.unisc.br/seer/index.php/direito/article/view/8464>. Acesso em: doi:http://dx.doi.org/10.17058/rdunisc.v3i50.8464. 